\title{
Rare-earth-regulated $\mathrm{Ru}-0$ interaction within the pyrochlore ruthenate for electrocatalytic oxygen evolution in acidic media
}

\author{
Hai Liu ${ }^{\dagger}$, Zhaolei Wang ${ }^{\dagger}$, Mengxuan $\mathrm{Li}^{\dagger}$, Xiuping Zhao, Xinxuan Duan, Shiyuan Wang, \\ Guoying Tan, Yun Kuang ${ }^{*}$ and Xiaoming Sun
}

\begin{abstract}
Ruthenium-based catalyst is one of the most active catalysts for oxygen evolution reaction (OER) in acid media. However, the strong bonding between the Ru sites and oxygen intermediates leads to high overpotential to trigger the OER process. Hence, pyrochlore rare-earth ruthenate $\left(\mathrm{RE}_{2}-\right.$ $\mathrm{Ru}_{2} \mathrm{O}_{7}$ ) structures with a series of rare-earth elements (Nd, Sm, $\mathrm{Gd}, \mathrm{Er}$, and $\mathrm{Yb}$ ) were constructed to tune the electronic structure of the Ru sites. Surface structure analysis indicated that the increase of the radius of the rare-earth cations resulted in higher content of defective oxygen (the percentage of the defective oxygen increased from $29.5 \%$ to $49.7 \%$ ) in the $\mathrm{RE}_{2} \mathrm{Ru}_{2} \mathrm{O}_{7}$ structure due to the weakened hybridization of the $\mathrm{Ru}-\mathrm{O}$ bond. This reduced the valence states of the $\mathrm{Ru}$ sites and enlarged the gap between the $4 \mathrm{~d}$ band center and the Fermi level $\left(E_{\mathrm{F}}\right)$ of $\mathrm{Ru}$, resulting in the weakened adsorption of oxygen intermediates and the improved OER performance in acid media. Among the as-prepared ruthenium pyrochlores, $\mathrm{Nd}_{2} \mathrm{Ru}_{2} \mathrm{O}_{7}$ displayed the lowest OER onset overpotential $(210 \mathrm{mV})$ and Tafel slope $\left(58.48 \mathrm{mV} \mathrm{dec}^{-1}\right)$, as well as 30 times higher intrinsic activity and much higher durability than the state-of-art $\mathrm{RuO}_{2}$ catalyst.
\end{abstract}

Keywords: oxygen evolution, ruthenium pyrochlore, rare earth elements, defective oxygen, $\mathrm{d}$ band center, valence state

\section{INTRODUCTION}

The increasing demand of energy and deteriorating environmental crisis call for alternative clean energy to fossil fuel. Electrochemical water splitting, which converts the electricity to chemical energy carrier $\left(\mathrm{H}_{2}\right)$, offers a viable strategy [1-6]. At present, proton exchange membrane (PEM) electrolyzers [7-9], operating in acidic media, have many advantages over alkaline electrolyzers, such as higher efficiency and higher hydrogen purity [10]. However, the sluggish kinetics of the anode reaction (OER) impedes the industrialization of PEM-based electrolysis [11]. Catalysts working in harsh environment especially at low $\mathrm{pH}$ are still limited to noble-metal-based materials such as $\mathrm{RuO}_{2}$ and $\mathrm{IrO}_{2}$ [12]. Theoretical studies reveal that optimal OER catalysts are supposed to possess neither too strong nor too weak binding strengths to oxygen intermediates [13]. Previous research reports that both $\mathrm{RuO}_{2}$ and $\mathrm{IrO}_{2}$ are expected to bind oxygen intermediates too strongly, and thereby hinder the desorption of oxygen intermediates, which restricts the OER performance in acidic media [14]. Compared with iridium dioxide, ruthenium dioxides possess higher activity and lower expense [15]. However, ruthenium dioxide is easily oxidized to $\mathrm{RuO}_{4}$ at high working potential $[16,17]$, which is expected to result in loss of active sites and instability during the OER process.

Confining $\mathrm{Ru}$ in multi-metal oxides has been reported as a promising strategy to enhance the activity and stability of Ru-based catalysts via modulating the coordination environment of $\mathrm{Ru}$ site [18-20]. For example, Retuerto et al. [21] reported $\mathrm{La}_{1.5} \mathrm{Sr}_{0.5} \mathrm{NiMn}_{0.5} \mathrm{Ru}_{0.5} \mathrm{O}_{6}$ double perovskite with $430 \mathrm{mV}$ overpotential and enhanced durability than $\mathrm{RuO}_{2}$. Miao et al. [22] reported a quadruple perovskite oxide $\mathrm{CaCu}_{3} \mathrm{Ru}_{4} \mathrm{O}_{12}$ as an active catalyst for acidic water oxidation, which exhibits better activity and stability than the state-of-the-art $\mathrm{RuO}_{2}$ due to optimized binding energy of oxygen intermediates. Recently, pyrochlore-type oxides $\left(\mathrm{A}_{2} \mathrm{~B}_{2} \mathrm{O}_{7}\right)$, which possess stable structure, such as $\mathrm{Y}_{2} \mathrm{Ru}_{2} \mathrm{O}_{7-\delta}$ [23], $\mathrm{Bi}_{2} \mathrm{Ir}_{2} \mathrm{O}_{7}$ [24],

State Key Laboratory of Chemical Resource Engineering, Beijing Advanced Innovation Center for Soft Matter Science and Engineering, Beijing University of Chemical Technology, Beijing 100029, China

${ }^{\dagger}$ These authors contributed equally to this paper.

* Corresponding authors (emails: kuangyun@mail.buct.edu.cn (Kuang Y); sunxm@mail.buct.edu.cn (Sun X)) 
and $\mathrm{PbBiIr}_{2} \mathrm{O}_{6.5}$ [25] have been reported as a sort of promising catalysts for oxidation reactions [26], in which A atoms close to $\mathrm{BO}_{6}$ octahedral can efficiently modulate the electron density of $\mathrm{B}$ atoms and stabilize the $\mathrm{B}$ sites [23].

Given the unique electron configuration of rare earth (RE) elements that the 4 f orbits are not fully filled [27,28], which could interact with the electrons of $\mathrm{Ru}$, herein a series of pyrochlore $\mathrm{RE}$ ruthenates $\left(\mathrm{RE}_{2} \mathrm{Ru}_{2} \mathrm{O}_{7}\right)$ electrocatalysts were synthesized by a simple sol-gel approach to explore the correlation between the electronic structure and the catalytic activity. It was noted that as the radius of the RE ions increased, the intrinsic activity of the catalysts displayed a significant improvement. Typically, $\mathrm{Nd}_{2} \mathrm{Ru}_{2} \mathrm{O}_{7}$ exhibited the best OER performance with the lowest onset overpotential $(210 \mathrm{mV}$, which is $170 \mathrm{mV}$ smaller than that of $\mathrm{RuO}_{2}$ ) and improved stability compared with $\mathrm{RuO}_{2}$. XPS analysis revealed that the relative content of oxygen vacancies increased as the RE radius increases, leading to reduced average valence state of $\mathrm{Ru}$. Density functional theory (DFT) calculation showed that the negative shift of $\mathrm{d}$ band center of Ru modulated the adsorption of oxygen intermediate, which promoted the OER kinetics.

\section{EXPERIMENTAL SECTION}

\section{Chemicals}

$\mathrm{RE}\left(\mathrm{NO}_{3}\right)_{3}$ (analytical reagent (AR) grade, Beijing HWRK Chem Co., LTD), $\mathrm{Ru}(\mathrm{NO})\left(\mathrm{NO}_{3}\right)_{x}(\mathrm{OH})_{y}$ (AR grade, J\&K), citric acid (AR grade, Beijing Chemical Works), and $\mathrm{HClO}_{4}$ (Beijing Chemical Works) were used.

\section{Synthesis of $\mathrm{RE}_{2} \mathrm{Ru}_{2} \mathbf{O}_{7}$}

All the $\mathrm{RE}_{2} \mathrm{Ru}_{2} \mathrm{O}_{7}$ catalysts were prepared by sol-gel approach. $\mathrm{RE}\left(\mathrm{NO}_{3}\right)_{3}(0.25 \mathrm{mmol})$ and $\mathrm{Ru}(\mathrm{NO})\left(\mathrm{NO}_{3}\right)_{x}(\mathrm{OH})_{y}$ $(1684.5 \mu \mathrm{L})$ were dissolved in $5 \mathrm{~mL}$ deionized (DI) water in a $20-\mathrm{mL}$ vial under ultrasonication. Then, $0.221 \mathrm{~g}$ of citric acid was added into the above solution for $30 \mathrm{~min}$. After that the vial was heated in an oil bath at $80^{\circ} \mathrm{C}$ for $8 \mathrm{~h}$ until all the water was vapored to get the powder precursor. The precursor then was transferred into a tube furnace, and heated at $600^{\circ} \mathrm{C}$ for $6 \mathrm{~h}$ and $1000^{\circ} \mathrm{C}$ for $12 \mathrm{~h}$ at the rate of $5^{\circ} \mathrm{C} \mathrm{min}^{-1}$.

\section{Material characterization}

The crystalline structures of all $\mathrm{RE}\left(\mathrm{NO}_{3}\right)_{3}$ samples were characterized by $\mathrm{X}$-ray diffraction (XRD) analysis using Shimadzu XRD-6000 diffractometer ( $\mathrm{Cu}$ Ka source, $\lambda=$ $1.5418 \AA$ ). The morphology was characterized by scan- ning electron microscope (SEM, Zeiss SUPRA 55, accelerating voltage of $20 \mathrm{kV}$ ) and transmission electron microscope (TEM, Hitachi-7700, $100 \mathrm{kV}$ ). The X-ray photoelectron spectroscopy (XPS) measurements were carried out with Thermo Electron ESCALAB250 XPS Spectrometer.

\section{Electrochemical measurement}

The catalyst ink was prepared by dispersing $5 \mathrm{mg}$ of the synthesized catalyst in the solution containing $1 \mathrm{~mL}$ of ethanol and $10 \mu \mathrm{L}$ of Nafion followed by ultrasonication for $1 \mathrm{~h}$. The catalyst ink $(30 \mu \mathrm{L})$ was deposited onto a glass carbon electrode (radius of $5 \mathrm{~mm}$ ). All the electrochemical measurements were performed in a three-electrode system with $\mathrm{Pt}$ sheet as the counter electrode and $\mathrm{Hg} / \mathrm{Hg}_{2} \mathrm{Cl}_{2}$ as the reference electrode. The $\mathrm{HClO}_{4}$ solution $\left(0.1 \mathrm{~mol} \mathrm{~L}^{-1}\right)$ was prepared by diluting the $\mathrm{HClO}_{4}$ $(0.4 \mathrm{~mL})$ with DI water $(49.6 \mathrm{~mL})$. All the measured potentials were converted to the reversible hydrogen electrode (RHE) and corrected with $i R$-compensation. OER measurements were performed in $0.1 \mathrm{~mol} \mathrm{~L}^{-1} \mathrm{HClO}_{4}$ electrolyte with a CHI Electrochemical Workstation (CHI $660 \mathrm{e})$ at a rotating speed of $1600 \mathrm{rpm}$. The polarization curves (linear sweep voltammetry (LSV)) were recorded with a scan rate of $5 \mathrm{mV} \mathrm{s}^{-1}$ after cyclic voltammetry (CV) curves (performed with a scan rate of $50 \mathrm{mV} \mathrm{s}^{-1}$ ) got stable. The electrochemically active surface area (ECSA) was estimated by measuring the capacitive current realated with double-layer charging from the scan-rate dependence of CV $[10,22]$. In details, the potential window of $\mathrm{CV}$ was $0.7-0.75 \mathrm{~V} v s$. RHE, in which no reactions occured. The scan rates were $2,3,4,5$, and $6 \mathrm{mV} \mathrm{s}^{-1}$. The double layer capacitance $\left(C_{\mathrm{dl}}\right)$ was evaluated by plotting $\Delta J=\left(J^{+}-\overline{J^{-}}\right) / 2$ at $0.725 \mathrm{~V} v$ s. RHE against the scan rate. The stability tests for $\mathrm{Nd}_{2} \mathrm{Ru}_{2} \mathrm{O}_{7}$ and $\mathrm{RuO}_{2}$ were carried out at $1 \mathrm{~mA} \mathrm{~cm}^{-2}$ following $i R$ correction.

\section{DFT calculation}

The density of state (DOS) for $\mathrm{Ru} 4 \mathrm{~d}$ and $\mathrm{O} 2 \mathrm{p}$ orbitals were acquired by DFT calculations, which were performed with the projector augmented wave (PAW) method using the Vienna Ab-initio Simulation Package (VASP). For all the calculations of $\mathrm{RE}_{2} \mathrm{Ru}_{2} \mathrm{O}_{7}$ and $\mathrm{RuO}_{2}$ models, the Generalized Gradient Approximation (GGA) of Perdew-Burke-Ernzerh (PBE) was used to describe the exchange and correlation energy density function. For $\mathrm{RE}_{2} \mathrm{Ru}_{2} \mathrm{O}_{7}$ and $\mathrm{RuO}_{2}$, the bulk lattice was optimized using the $4 \times 4 \times 4$ Monkhorst-Pack type of K-point sampling $[23,29]$. The models of $\mathrm{RE}_{2} \mathrm{Ru}_{2} \mathrm{O}_{7}$ and $\mathrm{RuO}_{2}$ bulk were displayed in the Supplementary information. The cutoff 
energy was set to be $400 \mathrm{eV}$ in this article. The maximum force and energy change were set as $0.01 \mathrm{eV} \AA^{-1}$ and 10$4 \mathrm{eV}$, respectively. The accuracy of all calculations was further improved by using DFT $+U$ method describing correlation for $3 \mathrm{~d}$ transition metal systems. The value of $U$ was 4 for $\mathrm{Ru}$ and the $U$ value was selected according to the literature [23].

\section{RESULTS AND DISCUSSION}

The $\mathrm{RE}_{2} \mathrm{Ru}_{2} \mathrm{O}_{7}$ materials were synthesized by the sol-gel approach followed by thermal treatment in air (Fig. 1a). The precursors were prepared by coordination of rareearth cations via citric acid [23]. The uniformly dispersed precursor solution ensured phase-pure synthesis of pyrochlore rare-earth ruthenate. The XRD patterns (Fig. 1b) of the as-prepared catalysts matched well with the stan- dard diffraction pattern of pyrochlore-type $\mathrm{RE}_{2} \mathrm{Ru}_{2} \mathrm{O}_{7}$ ( $\mathrm{PDF} \# 28-0673$ for $\mathrm{Nd}_{2} \mathrm{Ru}_{2} \mathrm{O}_{7}$ ), which indicated that the as-prepared catalysts were phase-pure and well-crystalized. In addition, the (222) crystalline facet at around $30^{\circ}$ in the enlarged diffraction patterns showed obvious positive shift from $\mathrm{Nd}_{2} \mathrm{Ru}_{2} \mathrm{O}_{7}$ to $\mathrm{Yb}_{2} \mathrm{Ru}_{2} \mathrm{O}_{7}$ (Fig. 1c), which could be attributed to the decrease of ionic radius from $\mathrm{Nd}(0.995 \AA)$ to $\mathrm{Yb}(0.858 \AA)$ [30]. The SEM images (Fig. 1d and Fig. S1) and TEM images (Fig. S2) indicated that the sizes of $\mathrm{RE}_{2} \mathrm{Ru}_{2} \mathrm{O}_{7}$ were in the range of 100 $200 \mathrm{~nm}$. The energy-dispersive spectroscopy (EDS) images (Fig. 1d and Fig. S3) revealed that the RE elements and ruthenium were uniformly distributed throughout the particle, indicating the successful synthesis of pyrochlore oxides. Two kinds of oxygen exist in this $\mathrm{RE}_{2} \mathrm{Ru}_{2} \mathrm{O}_{7}$ pyrochlore: one links $\mathrm{RE}_{2} \mathrm{O}$ and $\mathrm{Ru}_{2} \mathrm{O}_{6}$ to form a network

a

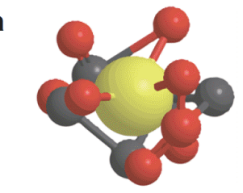

Coordinated Re

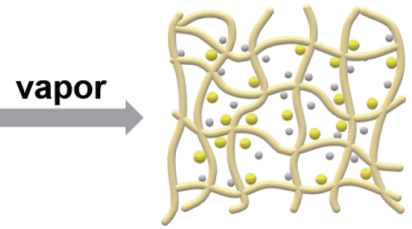

gel

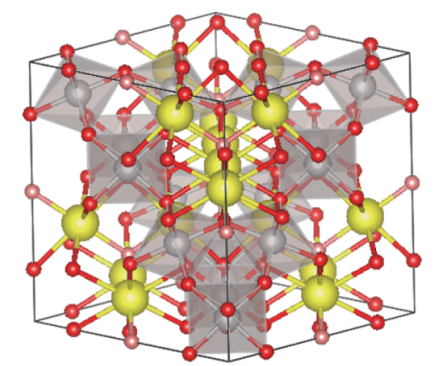

annealing

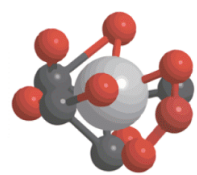

Coordinated Ru
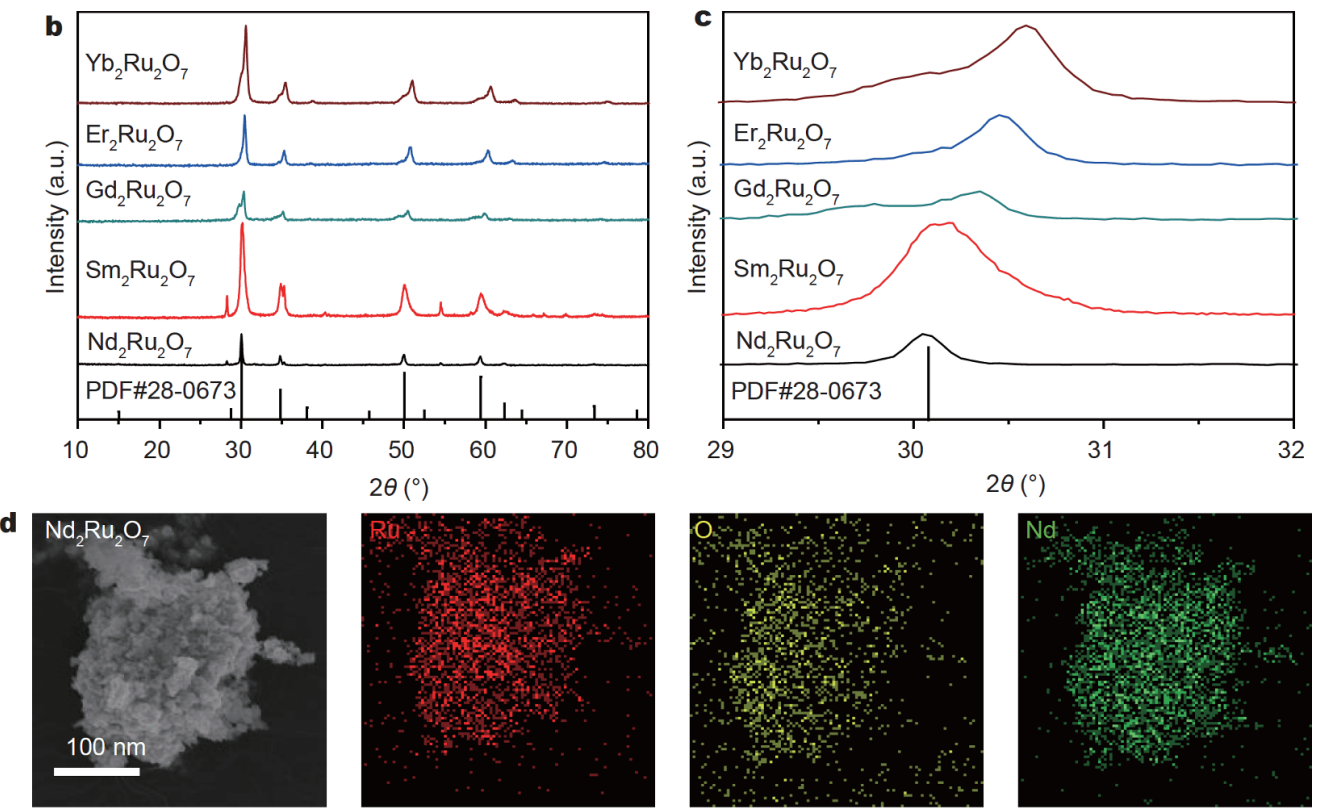

Figure 1 (a) Illustration of the synthetic route for $\mathrm{RE}_{2} \mathrm{Ru}_{2} \mathrm{O}_{7}$. (b) XRD patterns for $\mathrm{RE}_{2} \mathrm{Ru}_{2} \mathrm{O}_{7}$. (c) Expanded XRD patterns of the as-prepared $\mathrm{RE}_{2} \mathrm{Ru}_{2} \mathrm{O}_{7}$ in the $2 \theta=29^{\circ}-32^{\circ}$ region. (d) SEM image and EDS elemental mappings for $\mathrm{Nd}_{2} \mathrm{Ru}_{2} \mathrm{O}_{7}$. 
between the RE- and Ru-site, and the other connects to only the RE-site cations in the form of RE-O'-RE [31].

To investigate the effects caused by different RE elements on the activity of Ru pyrochlore catalysts, the OER performances of the $\mathrm{RE}_{2} \mathrm{Ru}_{2} \mathrm{O}_{7}$ catalysts were compared with commercial $\mathrm{RuO}_{2}$ in $0.1 \mathrm{~mol} \mathrm{~L}^{-1} \mathrm{HClO}_{4}$ electrolyte in a three-electrode configuration. Before the LSV curves were recorded, the CVs were performed until the catalysts exhibited a stable state. The LSV curves normalized to geometric area are shown in Fig. S4. To compare the intrinsic activities, all the current densities were normalized to the ECSA (Figs S5, S6) [32]. As shown in Fig. 2a, the OER activities of the $\mathrm{RE}_{2} \mathrm{Ru}_{2} \mathrm{O}_{7}$ electrocatalysts were closely related to the RE elements used. The $\mathrm{RE}$ ionic radii are $0.995,0.964,0.938,0.881$ and $0.858 \AA$ for Nd, Sm, Gd, Er and Yb, respectively. The OER activity exhibited a linear dependence on the $\mathrm{RE}$ ionic radius. From $\mathrm{Yb}$ to $\mathrm{Nd}$ used, the current density of the $\mathrm{RE}_{2} \mathrm{Ru}_{2} \mathrm{O}_{7}$ at the same potential increased gradually, and the onset potential decreased from $310 \mathrm{mV}(\mathrm{Yb})$ to $210 \mathrm{mV}(\mathrm{Nd})$. The current densities of $\mathrm{RE}_{2} \mathrm{Ru}_{2} \mathrm{O}_{7}$ and $\mathrm{RuO}_{2}$ at an applied potential of $1.54 \mathrm{~V}$ were compared (Fig. 2b). The $\mathrm{Nd}_{2} \mathrm{Ru}_{2} \mathrm{O}_{7}$ possessed the highest current density of $10 \mathrm{~A} \mathrm{~F}^{-1}$, which was $4.61,10.11,11.14,39.06$ and 30.30 times higher than that of $\mathrm{Sm}, \mathrm{Gd}, \mathrm{Er}, \mathrm{Yb}$ and $\mathrm{RuO}_{2}$ respectively. In addition, the overpotential of $\mathrm{RE}_{2} \mathrm{Ru}_{2} \mathrm{O}_{7}$ and $\mathrm{RuO}_{2}$ at a current density of $1 \mathrm{~A} \mathrm{~F}^{-1}$ were also compared. As shown in Fig. $2 \mathrm{~b}, \mathrm{Nd}_{2} \mathrm{Ru}_{2} \mathrm{O}_{7}$ exhibited the lowest overpotential of $220 \mathrm{mV}$, which was $60,90,96,190$ and $160 \mathrm{mV}$ smaller than the others respectively. As shown in Fig. $2 c$, the as-prepared $\mathrm{Nd}_{2} \mathrm{Ru}_{2} \mathrm{O}_{7}$ exhibited the highest ECSA-normalized intrinsic activity for OER in acid among ruthenium-based and iridium-based catalysts reported recently [33-39]. To better understand the kinetics of the $\mathrm{RE}_{2} \mathrm{Ru}_{2} \mathrm{O}_{7}$, the Tafel plots were measured (Fig. 2d). As reported in multi-electron reactions, different Tafel slope value means different rate determining step (RDS). The Tafel slope for $\mathrm{RE}_{2} \mathrm{Ru}_{2} \mathrm{O}_{7}$ was in the range of 60 $80 \mathrm{mV} \mathrm{dec}^{-1}\left(58.48,58.98,66.9,79.07,85.53 \mathrm{mV} \mathrm{dec}^{-1}\right.$ for $\mathrm{Nd}_{2} \mathrm{Ru}_{2} \mathrm{O}_{7}, \mathrm{Sm}_{2} \mathrm{Ru}_{2} \mathrm{O}_{7}, \mathrm{Gd}_{2} \mathrm{Ru}_{2} \mathrm{O}_{7}, \mathrm{Er}_{2} \mathrm{Ru}_{2} \mathrm{O}_{7}$ and $\mathrm{RuO}_{2}$ ) [40]. $\mathrm{Nd}_{2} \mathrm{Ru}_{2} \mathrm{O}_{7}$ possessed the lowest Tafel slope among the above mentioned catalysts, indicating the fastest OER kinetics [41]. However, $\mathrm{Yb}_{2} \mathrm{Ru}_{2} \mathrm{O}_{7}$ exhibited a much higher Tafel slope, suggesting a limited electron transfer. This indicated that the RE atoms could change the adsorption/desorption behavior of the catalytic active sites with the oxygen intermediates.

The electrochemical impedance spectroscopy
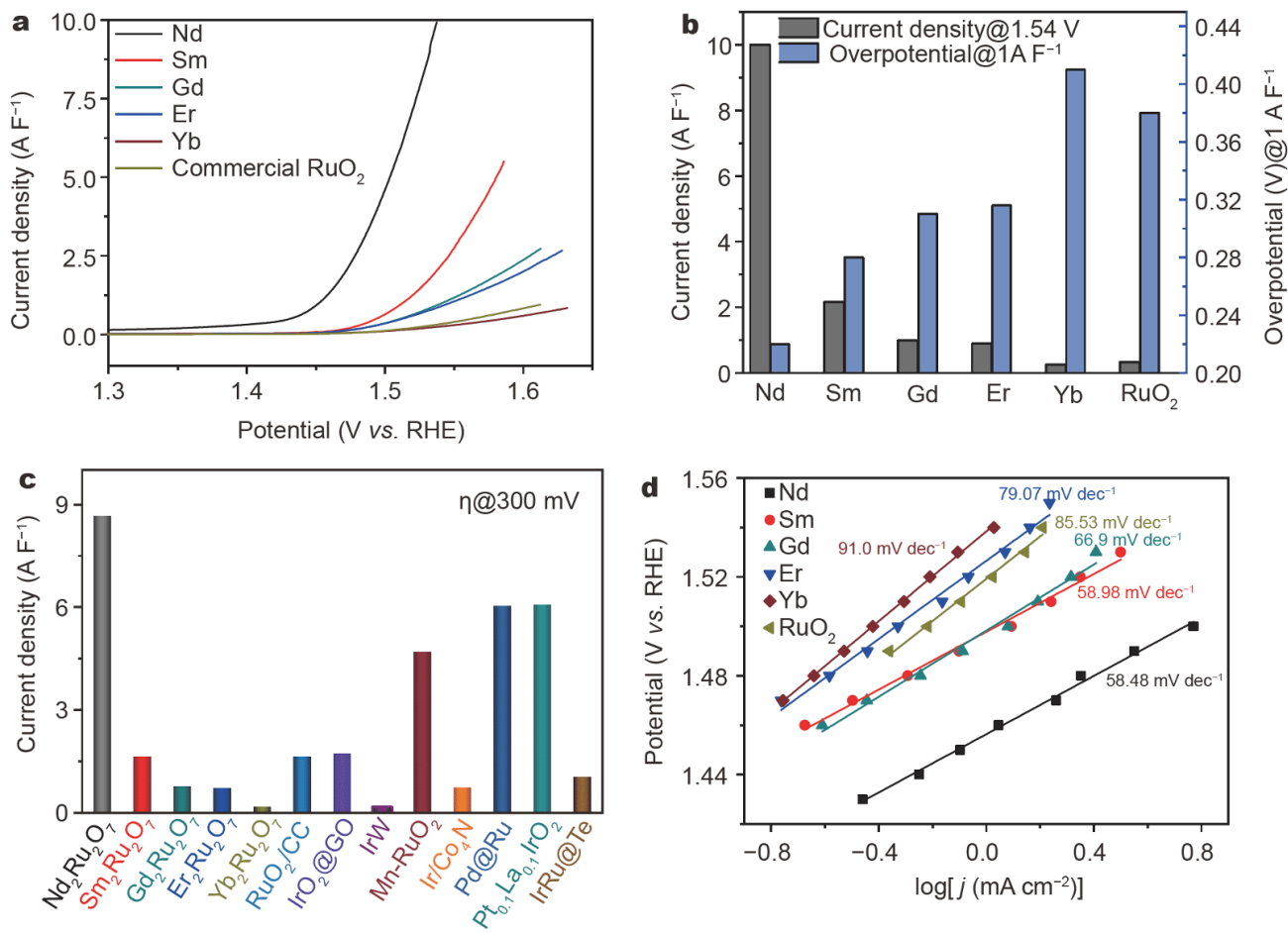

Figure 2 Electrocatalytic OER performance of the catalysts in $0.1 \mathrm{~mol} \mathrm{~L}^{-1} \mathrm{HClO}_{4}$ solution. (a) OER polarization curves of $\mathrm{RE}_{2} \mathrm{Ru}_{2} \mathrm{O}_{7}$ and commercial $\mathrm{RuO}_{2}$ with same loading. (b) Current density (left) @1.54 V vs. RHE and overpotential (right) @1 A F ${ }^{-1}$. (c) Comparison of intrinsic activity@300 mV between the as-prepared catalysts and recently-reported catalysts. (d) The Tafel plots of $\mathrm{RE}_{2} \mathrm{Ru}_{2} \mathrm{O}_{7}$ and commercial $\mathrm{RuO}_{2}$. 
implemented at $1.5 \mathrm{~V} v s$. RHE was adopted to further explore the OER kinetics. The Nyquist plots of $\mathrm{RE}_{2} \mathrm{Ru}_{2} \mathrm{O}_{7}$ catalysts showed a near-semicircle shape, in which the radius represented the charge transfer resistance. Fig. S7 showed that $\mathrm{Nd}_{2} \mathrm{Ru}_{2} \mathrm{O}_{7}$ and $\mathrm{Sm}_{2} \mathrm{Ru}_{2} \mathrm{O}_{7}$ had relatively smaller charge transfer resistance than $\mathrm{Gd}_{2} \mathrm{Ru}_{2} \mathrm{O}_{7}$, $\mathrm{Er}_{2} \mathrm{Ru}_{2} \mathrm{O}_{7}$ and $\mathrm{Yb}_{2} \mathrm{Ru}_{2} \mathrm{O}_{7}$, which indicated OER was more likely to occur. These results suggested that the intrinsic OER activity of $\mathrm{RE}_{2} \mathrm{Ru}_{2} \mathrm{O}_{7}$ strongly dependeds on the $\mathrm{RE}$ ions used. Especially, Nd, Sm, Gd and Er could improve the OER activity of $\mathrm{Ru}$, while $\mathrm{Yb}$ has a negative impact on the activity. The stability of $\mathrm{Nd}_{2} \mathrm{Ru}_{2} \mathrm{O}_{7}$ and $\mathrm{RuO}_{2}$ was tested under the same current density in $0.1 \mathrm{~mol} \mathrm{~L}^{-1}$
$\mathrm{HClO}_{4}$ (Fig. S8). $\mathrm{Nd}_{2} \mathrm{Ru}_{2} \mathrm{O}_{7}$ could maintain its performance for $8 \mathrm{~h}$, while $\mathrm{RuO}_{2}$ decayed in less than $1 \mathrm{~h}$. The improved stability demonstrated that RE atom could stabilize $\mathrm{Ru}$ sites and prevent their oxidation to higher valence state to be dissolved.

The surface chemical states were further investigated by XPS spectra (Fig. S9a). The $4 \mathrm{~d}$ spectra of RE were consistent with $\mathrm{RE}^{3+}$ spectra [42], indicating the RE existed as $\mathrm{RE}^{3+}$ on the surface (Fig. S9a). To further elaborate the valence states of Ru on the surface, Ru 3p spectra (Fig. 3a) were analyzed instead of $\mathrm{Ru} 3 \mathrm{~d}$ because the spectrum of carbon overlapped with the $\mathrm{Ru} 3 \mathrm{~d}$ spectra (Fig. S9c). The small negative shift of the $\mathrm{Ru} 3 \mathrm{p}$ peaks of $\mathrm{RE}_{2} \mathrm{Ru}_{2} \mathrm{O}_{7}$ in-
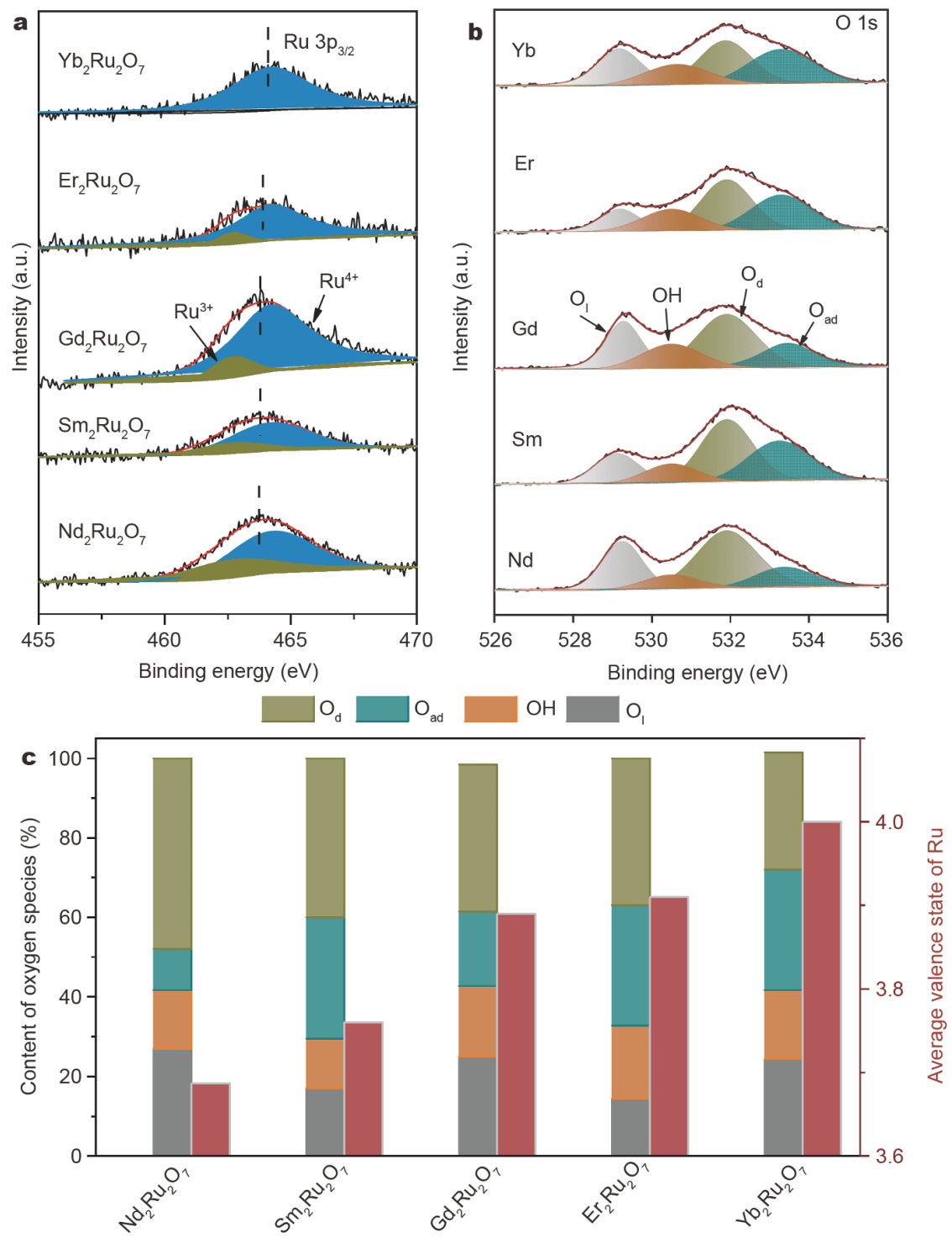

Figure 3 XPS spectra of $\mathrm{RE}_{2} \mathrm{Ru}_{2} \mathrm{O}_{7}$. (a) Ru 3p. (b) $\mathrm{O}$ 1s. (c) Calculated contents of oxygen species and average valence state of $\mathrm{Ru} \mathrm{for} \mathrm{RE}_{2} \mathrm{Ru}_{2} \mathrm{O}_{7}$. 
dicated decreased valence states of $\mathrm{Ru}$ from $\mathrm{Yb}_{2} \mathrm{Ru}_{2} \mathrm{O}_{7}$ to $\mathrm{Nd}_{2} \mathrm{Ru}_{2} \mathrm{O}_{7}$. All the $\mathrm{Ru} 3 \mathrm{p}$ spectra showed two peaks at $462.7 \mathrm{eV}$ and $464.2 \mathrm{eV}$, which corresponded to $\mathrm{Ru}^{3+}$ and $\mathrm{Ru}^{4+}$, respectively [35]. The ratios of $\mathrm{Ru}^{3+}$ to $\mathrm{Ru}^{4+}$ and the average valence states of $\mathrm{Ru}$ in the $\mathrm{RE}_{2} \mathrm{Ru}_{2} \mathrm{O}_{7}$ were calculated and listed in Fig. $3 \mathrm{c}$ and Table S1. We found that the average valence state decreased as the $\mathrm{RE}$ ionic radius increased, and $\mathrm{Nd}_{2} \mathrm{Ru}_{2} \mathrm{O}_{7}$ showed the lowest valence state of 3.68 in particular, which matched well with the relationship between activity and radius. Lower oxidation state of $\mathrm{Ru}$ possessed preferable OER kinetics, which could be attributed to more exposed unsaturated $\mathrm{Ru}$ active sites, thus possessing higher intrinsic activity $[43,44]$. Furthermore, improved stability was observed due to inhibited dissolution of $\mathrm{Ru}$ active sites as the valence state of $\mathrm{Ru}$ was below +4 .

$\mathrm{O}$ 1s spectra (Fig. 3b) were also analyzed to understand the valence state change of $\mathrm{Ru}$, peaks at $529.3 \mathrm{eV}$ were ascribed to the lattice oxygen $\left(\mathrm{O}_{1}\right)$ of $\mathrm{Ru}-\mathrm{O}$. Peaks at $530.5 \mathrm{eV}$ could be assigned to hydroxyl due to longtime exposure to air. The peaks locating at $533.3 \mathrm{eV}$ arise from the adsorbed oxygen $\left(\mathrm{O}_{\mathrm{ab}}\right)$. In addition, the peaks centered at $531.9 \mathrm{eV}$ corresponding to the defective oxygen $\left(\mathrm{O}_{\mathrm{d}}\right)$ [45], reflected the oxygen vacancies on the surface, which may account for the reduced valence state of $\mathrm{Ru}$. The percentage of the oxygen species was calculated to quantitatively analyze the difference of the surface oxygen state. As shown in Fig. $3 c$, the relative content of the defective oxygen for $\mathrm{Nd}_{2} \mathrm{Ru}_{2} \mathrm{O}_{7}, \mathrm{Sm}_{2} \mathrm{Ru}_{2} \mathrm{O}_{7}, \mathrm{Gd}_{2} \mathrm{Ru}_{2} \mathrm{O}_{7}$, $\mathrm{Er}_{2} \mathrm{Ru}_{2} \mathrm{O}_{7}$ and $\mathrm{Yb}_{2} \mathrm{Ru}_{2} \mathrm{O}_{7}$ were $47.9 \%, 40 \%, 38 \%, 36.3 \%$ and $29.5 \%$, showing a decreasing trend. The relative contents of the defective oxygen highly depended on the bonding strength of $\mathrm{Ru}-\mathrm{O}$, which was susceptible to the $\mathrm{RE}$. As the ionic radius increased from $\mathrm{Yb}$ to $\mathrm{Nd}$, the bond length of $\mathrm{Ru}-\mathrm{O}$ was elongated, which weakened the bonding strength of $\mathrm{Ru}-\mathrm{O}$ and resulted in increased defective oxygen concentration. To keep the material electrically neutral, the average valence state of $\mathrm{Ru}$ decreased with the increase of defective oxygen [46].

DFT calculations were employed to elucidate the activity difference caused by the RE elements. The band gaps of the $\mathrm{RE}_{2} \mathrm{Ru}_{2} \mathrm{O}_{7}$ were observed around the Fermi level (Fig. 4a), indicating conductive characteristics of the as-prepared materials, which were similar to semiconductor. The band gap showed increasing tendency (0.97, 0.86, 1.09 and $1.23 \mathrm{eV}$ for $\mathrm{Nd}_{2} \mathrm{Ru}_{2} \mathrm{O}_{7}, \mathrm{Sm}_{2} \mathrm{Ru}_{2} \mathrm{O}_{7}$, $\mathrm{Gd}_{2} \mathrm{Ru}_{2} \mathrm{O}_{7}$ and $\left.\mathrm{Er}_{2} \mathrm{Ru}_{2} \mathrm{O}_{7}\right)$ with the decrease of the $\mathrm{RE}$ ionic radius, corresponding to the increased resistivity (Fig. S7), which was also associated with $\mathrm{Ru} 4 \mathrm{~d}$ band center (Table S1) that shifted away from the Fermi level
[22]. The downshift of $\mathrm{Ru} 4 \mathrm{~d}$ band center increased the hybridization between $\mathrm{Ru} 4 \mathrm{~d}$ band and $\mathrm{O} 2 \mathrm{p}$ band from $\mathrm{Nd}$ to $\mathrm{Yb}$ (Fig. 4b), resulting in increased bonding strength of $\mathrm{Ru}-\mathrm{O}$. The strengthened $\mathrm{Ru}-\mathrm{O}$ from $\mathrm{Nd}$ to $\mathrm{Yb}$ impeded the releasing of lattice oxygen atoms during the annealing process, giving a reasonable explanation for the decreased defective oxygen content. In addition, the weakened metal-oxygen bonding allowed adjustment of the electronic structure of $\mathrm{Ru}$ that accommodated local charge changes during the OER process $[47,48]$, facilitating the OER kinetics.

Previous theoretical studies demonstrate that the OER intrinsic activity is strongly related to the metal-oxygen binding strength according to adsorbate evolution mechanism theory $[1,49]$. The optimal OER catalysts ought to have neither too strong nor too weak metal-oxygen binding strengths $[17,30]$. It is generally accepted that the metal-oxygen binding strength could be regulated by modulating the $\mathrm{d}$ band center of the active sites $[35,50]$. Thus, the correlation between the $\mathrm{Ru} 4 \mathrm{~d}$ band center and the intrinsic activity of $\mathrm{RE}_{2} \mathrm{Ru}_{2} \mathrm{O}_{7}$ and $\mathrm{RuO}_{2}$ was plotted in Fig. 4c, which displayed a volcano shape. The $\mathrm{RuO}_{2}$ catalyst with $\mathrm{Ru} 4 \mathrm{~d}$ band center located at $-0.89 \mathrm{eV}$ approaching the Fermi level possessed poor OER performance due to the strong adsorption of oxygen intermediates on the $\mathrm{Ru}$ site, which hindered the OER kinetics. A lower $\mathrm{d}$ band center yields a weakened metaloxygen bonding, and thus modulats the $\mathrm{Ru} 4 \mathrm{~d}$ band center away from Fermi level favoring OER kinetics [51].

Combining the electrochemical performance (Fig. 2a) and DFT simulation (Fig. 4c), the Ru $4 \mathrm{~d}$ band center of $\mathrm{Nd}_{2} \mathrm{Ru}_{2} \mathrm{O}_{7}$ was regulated to a moderate value which exhibited an extraordinary OER activity. When $\mathrm{Nb}$ was replaced by $\mathrm{Sm}, \mathrm{Gd}$ and $\mathrm{Yb}$, the $\mathrm{Ru} 4 \mathrm{~d}$ band center descended further away from the Fermi level, leading to worse OER activity than $\mathrm{Nd}$ because of impeded adsorption of oxygen intermediates, which hampered the OER kinetics. The $\mathrm{Ru} 4 \mathrm{~d}$ band center of $\mathrm{Yb}_{2} \mathrm{Ru}_{2} \mathrm{O}_{7}$ was about $-2.6 \mathrm{eV}$, which was too far from the Femi level, resulting in further decreased ability to adsorb oxygen intermediates on $\mathrm{Ru}$ sites [52].

\section{CONCLUSIONS}

In summary, we developed a class of pyrochlore RE ruthenates with regulated electronic structure of $\mathrm{Ru}$ sites, affording highly active and stable OER in acidic media that surpassed the state-of-art $\mathrm{RuO}_{2}$ catalyst. The ionic radius of the $\mathrm{RE}$ ion in this material was found related to the electronic state and the adsorption behavior of the active $\mathrm{Ru}$ center. The increase of $\mathrm{RE}$ ionic radius in- 

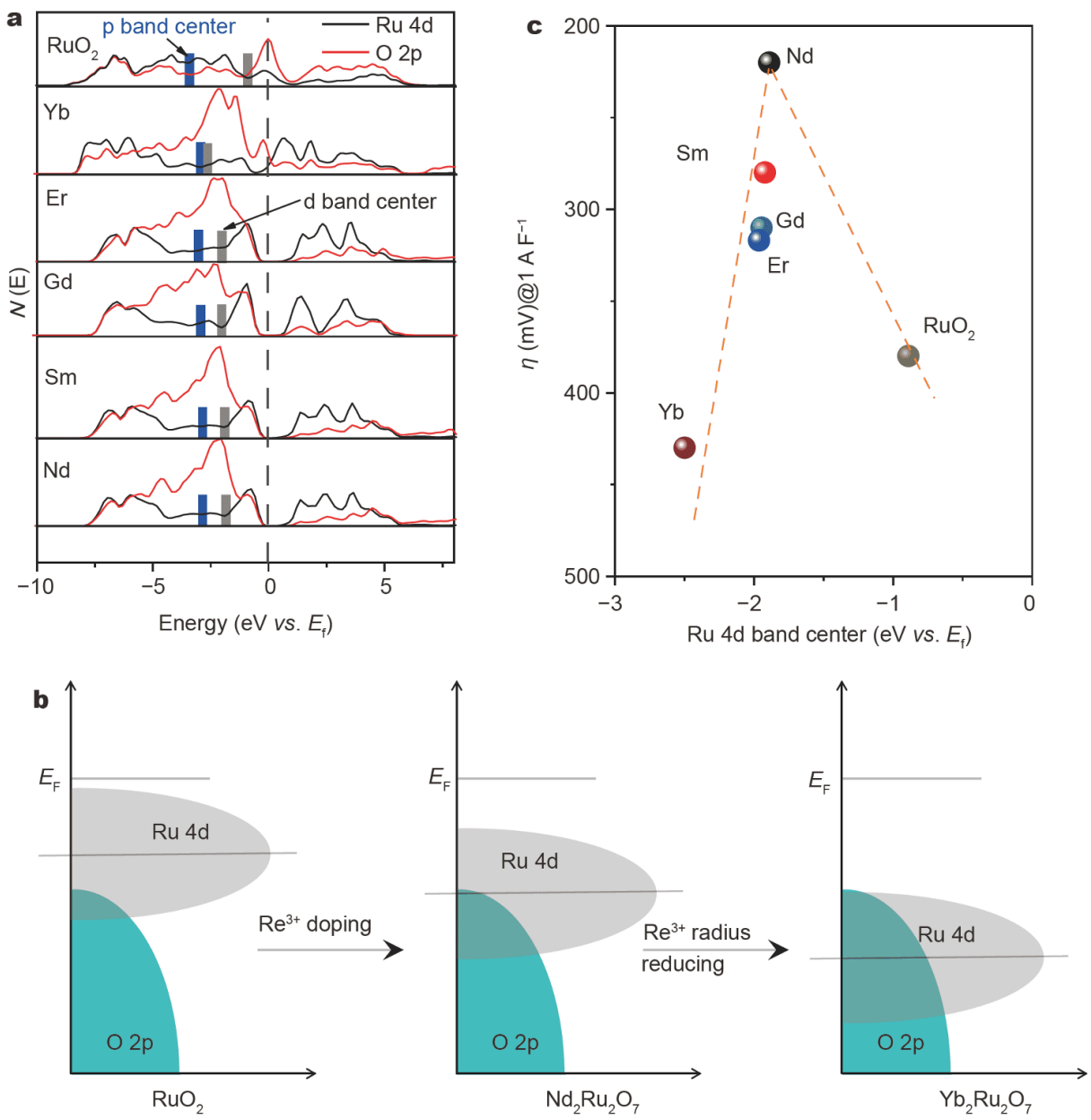

Figure 4 (a) Calculated densities of the state of $\mathrm{Ru} 4 \mathrm{~d}$ and $\mathrm{O} 2 \mathrm{p}$ for $\mathrm{RE}_{2} \mathrm{Ru}_{2} \mathrm{O}_{7}$. (b) Schematic rigid band diagram for $\mathrm{RuO}_{2}, \mathrm{Nd}_{2} \mathrm{Ru}_{2} \mathrm{O}_{7}$ and $\mathrm{Yb}_{2} \mathrm{Ru}_{2} \mathrm{O}_{7}$. (c) Correlation between $\mathrm{Ru} 4 \mathrm{~d}$ band center and OER activity.

troduced defective oxygen and reduced the valence state of $\mathrm{Ru}$ by weakening the hybridization of $\mathrm{Ru}-\mathrm{O}$ bond within the material. This coordination environment regulation and electronic structure tuning strategy might also be applicable in other $\mathrm{ABO}_{x}$ or multi-metallic oxide materials for higher OER performances in neutral or acid media.

Received 25 September 2020; accepted 23 November 2020; published online 4 February 2021

1 Man IC, Su H, CalleVallejo F, et al. Universality in oxygen evolution electrocatalysis on oxide surfaces. ChemCatChem, 2011, 3: $1159-1165$

2 Seh ZW, Kibsgaard J, Dickens CF, et al. Combining theory and experiment in electrocatalysis: Insights into materials design. Science, 2017, 355: eaad4998

3 Ni B, Zhang Q, Ouyang C, et al. The synthesis of sub-nano-thick Pd nanobelt-based materials for enhanced hydrogen evolution reaction activity. CCS Chem, 2020, 2: 642-654
4 Lin $\mathrm{H}$, Sun B, Wang $\mathrm{H}$, et al. Unique 1D Cd $\mathrm{Cd}_{1-x} \mathrm{Zn}_{x} \mathrm{~S} @ \mathrm{O}-\mathrm{MoS}_{2} / \mathrm{NiO}_{x}$ nanohybrids: Highly efficient visible-light-driven photocatalytic hydrogen evolution via integrated structural regulation. Small, 2019, 15: 1804115

5 Zhang S, Lv F, Zhang X, et al. Ni@RuM (M=Ni or Co) core@shell nanocrystals with high mass activity for overall water-splitting catalysis. Sci China Mater, 2019, 62: 1868-1876

6 Zhuang G, Chen Y, Zhuang Z, et al. Oxygen vacancies in metal oxides: recent progress towards advanced catalyst design. Sci China Mater, 2020, 63: 2089-2118

7 Lee Y, Suntivich J, May KJ, et al. Synthesis and activities of rutile $\mathrm{IrO}_{2}$ and $\mathrm{RuO}_{2}$ nanoparticles for oxygen evolution in acid and alkaline solutions. J Phys Chem Lett, 2012, 3: 399-404

8 Nong HN, Oh HS, Reier T, et al. Oxide-supported $\mathrm{IrNiO}_{x}$ coreshell particles as efficient, cost-effective, and stable catalysts for electrochemical water splitting. Angew Chem Int Ed, 2015, 54: 2975-2979

9 McCrory CCL, Jung S, Ferrer IM, et al. Benchmarking hydrogen evolving reaction and oxygen evolving reaction electrocatalysts for solar water splitting devices. J Am Chem Soc, 2015, 137: 4347-4357

10 Shang C, Cao C, Yu D, et al. Electron correlations engineer cata- 
lytic activity of pyrochlore iridates for acidic water oxidation. Adv Mater, 2018, 30: 1805104

11 Zhou D, Wang S, Jia $\mathrm{Y}$, et al. NiFe hydroxide lattice tensile strain: enhancement of adsorption of oxygenated intermediates for efficient water oxidation catalysis. Angew Chem Int Ed, 2019, 58: 736740

12 Zhang T, Liao SA, Dai LX, et al. Ir-Pd nanoalloys with enhanced surface-microstructure-sensitive catalytic activity for oxygen evolution reaction in acidic and alkaline media. Sci China Mater, 2018, 61: 926-938

13 Dickens CF, Montoya JH, Kulkarni AR, et al. An electronic structure descriptor for oxygen reactivity at metal and metal-oxide surfaces. Surf Sci, 2019, 681: 122-129

14 Shan J, Ling T, Davey K, et al. Transition-metal-doped RuIr bifunctional nanocrystals for overall water splitting in acidic environments. Adv Mater, 2019, 31: 1900510

15 Tian Y, Wang S, Velasco E, et al. A Co-doped nanorod-like $\mathrm{RuO}_{2}$ electrocatalyst with abundant oxygen vacancies for acidic water oxidation. iScience, 2020, 23: 100756

16 Yao Y, Hu S, Chen W, et al. Engineering the electronic structure of single atom $\mathrm{Ru}$ sites via compressive strain boosts acidic water oxidation electrocatalysis. Nat Catal, 2019, 2: 304-313

17 Cui X, Ren P, Ma C, et al. Robust interface Ru centers for highperformance acidic oxygen evolution. Adv Mater, 2020, 32: 1908126

$18 \mathrm{Su}$ J, Ge R, Jiang K, et al. Assembling ultrasmall copper-doped ruthenium oxide nanocrystals into hollow porous polyhedra: Highly robust electrocatalysts for oxygen evolution in acidic media. Adv Mater, 2018, 30: 1801351

19 Shan J, Raziq F, Humayun M, et al. Improved charge separation and surface activation via boron-doped layered polyhedron $\mathrm{SrTiO}_{3}$ for co-catalyst free photocatalytic $\mathrm{CO}_{2}$ conversion. Appl Catal BEnviron, 2017, 219: 10-17

20 Shen J, Li Y, Zhao $\mathrm{H}$, et al. Modulating the photoelectrons of g$\mathrm{C}_{3} \mathrm{~N}_{4}$ via coupling $\mathrm{MgTi}_{2} \mathrm{O}_{5}$ as appropriate platform for visiblelight-driven photocatalytic solar energy conversion. Nano Res, 2019, 12: 1931-1936

21 Retuerto $\mathrm{M}$, Calle-Vallejo F, Pascual L, et al. $\mathrm{La}_{1.5} \mathrm{Sr}_{0.5} \mathrm{NiMn}_{0.5^{-}}$ $\mathrm{Ru}_{0.5} \mathrm{O}_{6}$ double perovskite with enhanced ORR/OER bifunctional catalytic activity. ACS Appl Mater Interfaces, 2019, 11: 2145421464

22 Miao X, Zhang L, Wu L, et al. Quadruple perovskite ruthenate as a highly efficient catalyst for acidic water oxidation. Nat Commun, 2019, 10: 3809

23 Kim J, Shih PC, Tsao KC, et al. High-performance pyrochlore-type yttrium ruthenate electrocatalyst for oxygen evolution reaction in acidic media. J Am Chem Soc, 2017, 139: 12076-12083

24 Sun W, Liu JY, Gong XQ, et al. OER activity manipulated by $\mathrm{IrO}_{6}$ coordination geometry: an insight from pyrochlore iridates. Sci Rep, 2016, 6: 38429

25 Parrondo J, George M, Capuano C, et al. Pyrochlore electrocatalysts for efficient alkaline water electrolysis. J Mater Chem A, 2015, 3: 10819-10828

26 Chen J, Shao Y, Li D. An antimonate pyrochlore $\left(\mathrm{H}_{1.23} \mathrm{Sr}_{0.45} \mathrm{SbO}_{3.48}\right)$ for photocatalytic oxidation of benzene: effective oxygen usage and excellent activity. J Mater Chem A, 2017, 5: 937-941

27 Ji S, Qu Y, Wang T, et al. Rare-earth single erbium atoms for enhanced photocatalytic $\mathrm{CO}_{2}$ reduction. Angew Chem Int Ed, 2020, 59: 10651-10657

$28 \mathrm{Xu} \mathrm{H}, \mathrm{Yu} \mathrm{W}$, Pan K, et al. Confinement and antenna effect for ultrasmall $\mathrm{Y}_{2} \mathrm{O}_{3}: \mathrm{Eu}^{3+}$ nanocrystals supported by MOF with enhanced near-UV light absorption thereby enhanced luminescence and excellently multifunctional applications. Nano Res, 2021, 14: 720-729

29 Li P, Duan X, Kuang Y, et al. Tuning electronic structure of NiFe layered double hydroxides with vanadium doping toward high efficient electrocatalytic water oxidation. Adv Energy Mater, 2018, 8: 1703341

30 Lebedev D, Povia M, Waltar K, et al. Highly active and stable iridium pyrochlores for oxygen evolution reaction. Chem Mater, 2017, 29: 5182-5191

31 Teng Z, Zhu L, Tan Y, et al. Synthesis and structures of highentropy pyrochlore oxides. J Eur Ceramic Soc, 2020, 40: 1639-1643

$32 \mathrm{Du} \mathrm{CF}$, Sun $\mathrm{X}, \mathrm{Yu} \mathrm{H}$, et al. Synergy of $\mathrm{Nb}$ doping and surface alloy enhanced on water-alkali electrocatalytic hydrogen generation performance in Ti-based MXene. Adv Sci, 2019, 6: 1900116

33 Chen J, Cui P, Zhao G, et al. Low-coordinate iridium oxide confined on graphitic carbon nitride for highly efficient oxygen evolution. Angew Chem Int Ed, 2019, 58: 12540-12544

34 Lv F, Feng J, Wang K, et al. Iridium-tungsten alloy nanodendrites as $\mathrm{pH}$-universal water-splitting electrocatalysts. ACS Cent Sci, 2018, 4: 1244-1252

35 Chen $\mathrm{S}$, Huang $\mathrm{H}$, Jiang $\mathrm{P}$, et al. $\mathrm{Mn}$-doped $\mathrm{RuO}_{2}$ nanocrystals as highly active electrocatalysts for enhanced oxygen evolution in acidic media. ACS Catal, 2019, 10: 1152-1160

36 Tackett BM, Sheng W, Kattel S, et al. Reducing iridium loading in oxygen evolution reaction electrocatalysts using core-shell particles with nitride cores. ACS Catal, 2018, 8: 2615-2621

$37 \mathrm{Hu} \mathrm{Y,} \mathrm{Luo} \mathrm{X,} \mathrm{Wu} \mathrm{G,} \mathrm{et} \mathrm{al.} \mathrm{Engineering} \mathrm{the} \mathrm{atomic} \mathrm{layer} \mathrm{of} \mathrm{RuO}_{2}$ on PdO nanosheets boosts oxygen evolution catalysis. ACS Appl Mater Interfaces, 2019, 11: 42298-42304

38 Hao S, Wang Y, Zheng G, et al. Tuning electronic correlations of ultra-small $\mathrm{IrO}_{2}$ nanoparticles with $\mathrm{La}$ and $\mathrm{Pt}$ for enhanced oxygen evolution performance and long-durable stability in acidic media. Appl Catal B-Environ, 2020, 266: 118643

$39 \mathrm{Xu} \mathrm{J}$, Lian Z, Wei B, et al. Strong electronic coupling between ultrafine iridium-ruthenium nanoclusters and conductive, acidstable tellurium nanoparticle support for efficient and durable oxygen evolution in acidic and neutral media. ACS Catal, 2020, 10: 3571-3579

40 Lin Y, Tian Z, Zhang L, et al. Chromium-ruthenium oxide solid solution electrocatalyst for highly efficient oxygen evolution reaction in acidic media. Nat Commun, 2019, 10: 162

41 Gao J, Xu CQ, Hung SF, et al. Breaking long-range order in iridium oxide by alkali ion for efficient water oxidation. J Am Chem Soc, 2019, 141: 3014-3023

42 Sanders MB, Krizan JW, Cava RJ. $\mathrm{RE}_{3} \mathrm{Sb}_{3} \mathrm{Zn}_{2} \mathrm{O}_{14}(\mathrm{RE}=\mathrm{La}, \mathrm{Pr}, \mathrm{Nd}$, $\mathrm{Sm}, \mathrm{Eu}, \mathrm{Gd}$ ): a new family of pyrochlore derivatives with rare earth ions on a 2D Kagome lattice. J Mater Chem C, 2016, 4: 541-550

$43 \mathrm{Ge} \mathrm{R}, \mathrm{Li} \mathrm{L}, \mathrm{Su}$ J, et al. Ultrafine defective $\mathrm{RuO}_{2}$ electrocatayst integrated on carbon cloth for robust water oxidation in acidic media. Adv Energy Mater, 2019, 9: 1901313

44 Li P, Wang M, Duan X, et al. Boosting oxygen evolution of singleatomic ruthenium through electronic coupling with cobalt-iron layered double hydroxides. Nat Commun, 2019, 10: 1711

45 Liu G, Li J, Fu J, et al. An oxygen-vacancy-rich semiconductorsupported bifunctional catalyst for efficient and stable zinc-air batteries. Adv Mater, 2018, 30: 1806761

46 Tong $\mathrm{Y}$, Guo H, Liu D, et al. Vacancy engineering of iron-doped $\mathrm{W}_{18} \mathrm{O}_{49}$ nanoreactors for low-barrier electrochemical nitrogen re- 
duction. Angew Chem Int Ed, 2020, 59: 7356-7361

47 Diaz-Morales O, Raaijman S, Kortlever R, et al. Iridium-based double perovskites for efficient water oxidation in acid media. Nat Commun, 2016, 7: 12363

48 Zhang L, Yuan H, Wang L, et al. The critical role of electrochemically activated adsorbates in neutral OER. Sci China Mater, 2020, 63: 2509-2516

49 Rossmeisl J, Logadottir A, Nørskov JK. Electrolysis of water on (oxidized) metal surfaces. Chem Phys, 2005, 319: 178-184

50 Norsko JK. Chemisorption on metal surfaces. Rep Prog Phys, 1999, 53: $1253-1295$

51 Chen Z, Song Y, Cai J, et al. Tailoring the d-band centers enables $\mathrm{Co}_{4} \mathrm{~N}$ nanosheets to be highly active for hydrogen evolution catalysis. Angew Chem Int Ed, 2018, 57: 5076-5080

52 Song Q, Li J, Wang S, et al. Enhanced electrocatalytic performance through body enrichment of Co-based bimetallic nanoparticles in situ embedded porous N-doped carbon spheres. Small, 2019, 15: 1903395

Acknowledgements This work was supported by the National Key Research and Development Project (2018YFB1502401), the National Natural Science Foundation of China (21771018 and 21875004), the Royal Society and Newton Fund through Newton Advanced Fellowship award (NAF $\backslash R 1 \backslash 191294$ ), the Program for Changjiang Scholars and Innovation Research Team in the University (IRT1205), the Fundamental Research Funds for the Central Universities, and the long-term subsidy mechanism from the Ministry of Finance and the Ministry of Education of China.

Author contributions Liu H, Wang Z, Kuang Y and Sun X conceived the research; Liu $H$, Wang $Z$ and Wang $S$ designed and carried out the experiments; Zhao X, Duan X, Liu $\mathrm{H}$ and Wang $\mathrm{Z}$ did the DFT calculations; Liu H, Wang $\mathrm{Z}$ and $\mathrm{Li} \mathrm{M}$ draw the figures; all the authors analyzed the data; Liu H, Wang Z, Kuang Y and Sun X wrote the paper.

Conflict of interest The authors declare no conflict of interest.

Supplementary information Supporting data are available in the online version of the paper.

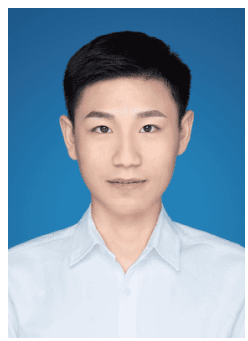

Hai Liu is a PhD student at Beijing University of Chemical Technology (BUCT) under the supervision of Prof. Xiaoming Sun. His current research focuses on electrocatalytic water oxidation in acidic media.

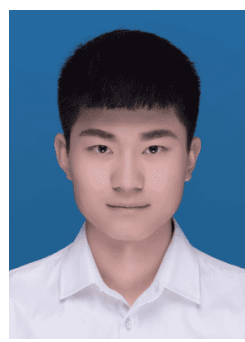

Zhaolei Wang is a PhD student at BUCT under the supervision of Prof. Xiaoming Sun. His current research focuses on electrocatalytic water oxidation.

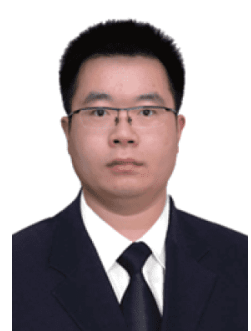

Yun Kuang obtained his $\mathrm{BE}$ and $\mathrm{PhD}$ degrees from BUCT in 2010 and 2015, respectively. He then joined the faculty of BUCT. He is now an associate professor in chemistry at the College of Chemistry, BUCT and a visiting associate professor in the Department of Chemistry, Stanford University. His current research interest mainly focuses on the synthesis, structure regulation and assembly of transitional metal-based nanostructures under control, as well as their application in catalysis and energy-related area.

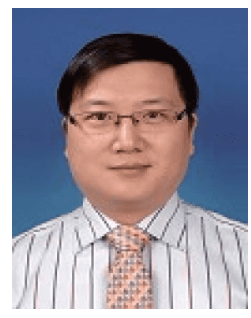

Xiaoming Sun received his BSc degree and $\mathrm{PhD}$ degree from the Department of Chemistry, Tsinghua University in 2000 and 2005, respectively. After postdoctoral work at Stanford University, he joined the State Key Laboratory of Chemical Resource Engineering, BUCT in 2008. His main research interests focus on parathion and assembly of inorganic nanostructures, synthesis and separation of carbon nanomaterials and their composites, and structure control and opto-/eletro-property investigations of oxide nanoarrays.

\section{稀土调控烧绿石钓酸盐中钓氧相互作用用于酸性 析氧反应}

刘海, 王兆磊 ${ }^{\dagger}$, 李梦㨽 ${ }^{\dagger}$, 赵秀萍, 段欣漩, 王士元, 谭国英, 广允", 孙晓明

摘要 钓 $(\mathrm{Ru})$ 基催化剂是酸性介质中析氧反应(OER)最为活泼的催 化剂之一. 然而, $\mathrm{Ru}$ 活性位点与含氧中间产物之间的强键合导致析 氧反应过电势较高. 本文, 利用一系列稀土元素 $(\mathrm{Nd} 、 \mathrm{Sm} 、 \mathrm{Gd} 、 \mathrm{Er}$ 和 $\mathrm{Yb}$ )构建了烧绿石型稀土钉酸盐 $\left(\mathrm{RE}_{2} \mathrm{Ru}_{2} \mathrm{O}_{7}\right)$ 结构来调整 $\mathrm{Ru}$ 位点 的电子结构. 表面结构分析表明, 由于 $\mathrm{Ru}-\mathrm{O}$ 键杂化减弱, 随着稀土 离子半径的增大, $\mathrm{RE}_{2} \mathrm{Ru}_{2} \mathrm{O}_{7}$ 结构中缺陷氧含量增加(缺陷氧的比例 从 $29.5 \%$ 增加到 $49.7 \%$ ). 降低了的 $\mathrm{Ru}$ 的价态, 扩大了 $\mathrm{Ru}$ 的 $4 \mathrm{~d}$ 能带中 心与费米能级 $\left(E_{\mathrm{F}}\right)$ 之间的间隙, 从而削弱了对氧中间体的吸附, 提 高了酸性介质中的OER性能. 在所制备的钉烧绿石中, $\mathrm{Nd}_{2} \mathrm{Ru}_{2} \mathrm{O}_{7}$ 表 现出最低的 O E R 起始过电势 (210 m V ) 和 T a f e l 斜率 $\left(58.48 \mathrm{mV} \mathrm{dec}{ }^{-1}\right)$, 并且比最先进的 $\mathrm{RuO}_{2}$ 催化剂具有高30倍的固有 活性和更好的耐久性. 